\title{
Antiviral Drug Ivermectin at Nanomolar Concentrations Inhibits Glycine-Induced Chloride Current in Rat Hippocampal Neurons
}

\author{
J. V. Bukanova, E. I. Solntseva, R. V. Kondratenko, and V. G. Skrebitsky
}

Translated from Byulleten'Eksperimental'noi Biologii i Meditsiny, Vol. 170, No. 11, pp. 613-617, November, 2020 Original article submitted on July 27, 2020

\begin{abstract}
Ivermectin (IVM) belongs to the class of macrocyclic lactones, which is used as an antiparasitic agent. At present, the researchers focus on possibility to use IVM in treatment of certain forms of cancer and viral diseases such as COVID-19. The mechanisms of IVM action are not clear. It is assumed that IVM affects chloride channels and increases cytoplasmic concentration of chloride. This study examines the effect of IVM on chloride currents induced by glycine $\left(I_{\mathrm{Gly}}\right)$. Experiments were carried out on isolated pyramidal neurons of the rat hippocampus with whole-cell patch clamp. A short-term $(600 \mathrm{msec})$ application of IVM in a concentration of $10 \mu \mathrm{M}$ induced a slow inward current, which persisted after washing the neurons. The low concentrations (0.1-1000 nM) of IVM did not induce any novel current, but it rapidly and reversibly reduced the peak amplitude and accelerated desensitization of $I_{\mathrm{Gly}}$ in a dose-dependent manner. The threshold concentrations of IVM sufficient to reduce peak amplitude of $I_{\text {Gly }}$ and to accelerate desensitization of $I_{\text {Gly }}$ were $100 \mathrm{nM}$ and $0.1 \mathrm{nM}$, respectively. The study revealed a high sensitivity of neuronal glycine receptors to IVM.
\end{abstract}

Key Words: glycine receptor; ivermectin; hippocampus; patch clamp

Ivermectin (IVM) belongs to the class of macrocyclic lactones. It is a product of secretion of Streptomyces bacteria, which live in the soil. IVM is known for pronounced antiparasitic action, so it is widely used in veterinary and therapeutics against helminths and some insects [6]. In addition, IVM exerts many other physiological effects such as anticonvulsant action [4], alleviation of neuropathic pain [13], destruction of the malignant leukemic cells $[5,6,9]$. A present, a promising vista to use IVM as chemotherapeutic medication in treatment of certain types of cancer [5,7] and as antiviral agent against COVID-19 [3] is widely discussed. A large number of molecular

Research Center of Neurology, Moscow Russia. Address for correspondence: synaptology@mail.ru. E. I. Solntseva targets have been identified for IVM to exert its physiological effects [5]. Of them, an important role is given to ligand-operated chloride channels in plasmalemma, which can increase the intracellular concentration of chloride and hyperpolarize the cell membrane as a result of binding with IVM. In neurons of invertebrate animals, IVM in nanomolar concentrations enhances the chloride current through glutamate-activated chloride channels (GluClC) [14]. In mammalian cells, it activates GABA-dependent chloride channels, although at higher concentrations [4]. However, the data on IVM-induced modification of glycine-activated chloride current $\left(I_{\mathrm{Gly}}\right)$ are contradictory. Actually, IVM stimulates $I_{\mathrm{Gly}}$ due to interaction with recombinant glycine receptors (GlyR) [8], but inhibits the cortical neurons in rats [4]. 
This work was designed to study the effects of IVM on $I_{\mathrm{Gly}}$ in pyramidal neurons of rat hippocampus.

\section{MATERIALS AND METHODS}

Experiments were carried out on pyramidal neurons isolated from hippocampal CA3 region of 11-14-dayold Wistar rat. Glycine was applied to neuron at concentration of 100 or $500 \mu \mathrm{M}$ via a $0.1-\mathrm{mm}$ glass pipette during its rapid lateral displacement. The application time and interapplication interval were 600 msec and 30-40 sec, respectively. The ionic currents were recorded with patch clamp in whole cell configuration [1]. The holding potential was $-70 \mathrm{mV}$. The recording pipette was filed with solution containing (in $\mathrm{mM}$ ): $40 \mathrm{CsF}, 100 \mathrm{CsCl}, 5 \mathrm{EGTA}, 0.5 \mathrm{CaCl}_{2}, 4 \mathrm{MgCl}_{2}$,
6 NaATP, and 5 HEPES (pH 7.3). The extracellular perfusion solution contained (in $\mathrm{mM}$ ): $140 \mathrm{NaCl}$, $3 \mathrm{KCl}, 3 \mathrm{CaCl}_{2}, 3_{\mathrm{MgCl}_{2}}, 10 \mathrm{D}$-glucose, and 10 HEPES hemisodium ( $\mathrm{pH} 7.4)$. The perfusion rate was $0.6 \mathrm{ml} /$ min. IVM was purchased from Tocris. The reagents of physiological saline were purchased from Sigma.

The results were analyzed statistically using GraphPad Prism software and unpaired Student's $t$ test. The data were averaged from the measurements in several neurons $(n=7-8)$ and presented as $m \pm S E M$.

\section{RESULTS}

A short-term application $(600 \mathrm{msec})$ of glycine to hippocampal pyramidal neurons induced $I_{\mathrm{Gly}}$ [2]. Dependence of its amplitude on concentration of glycine was
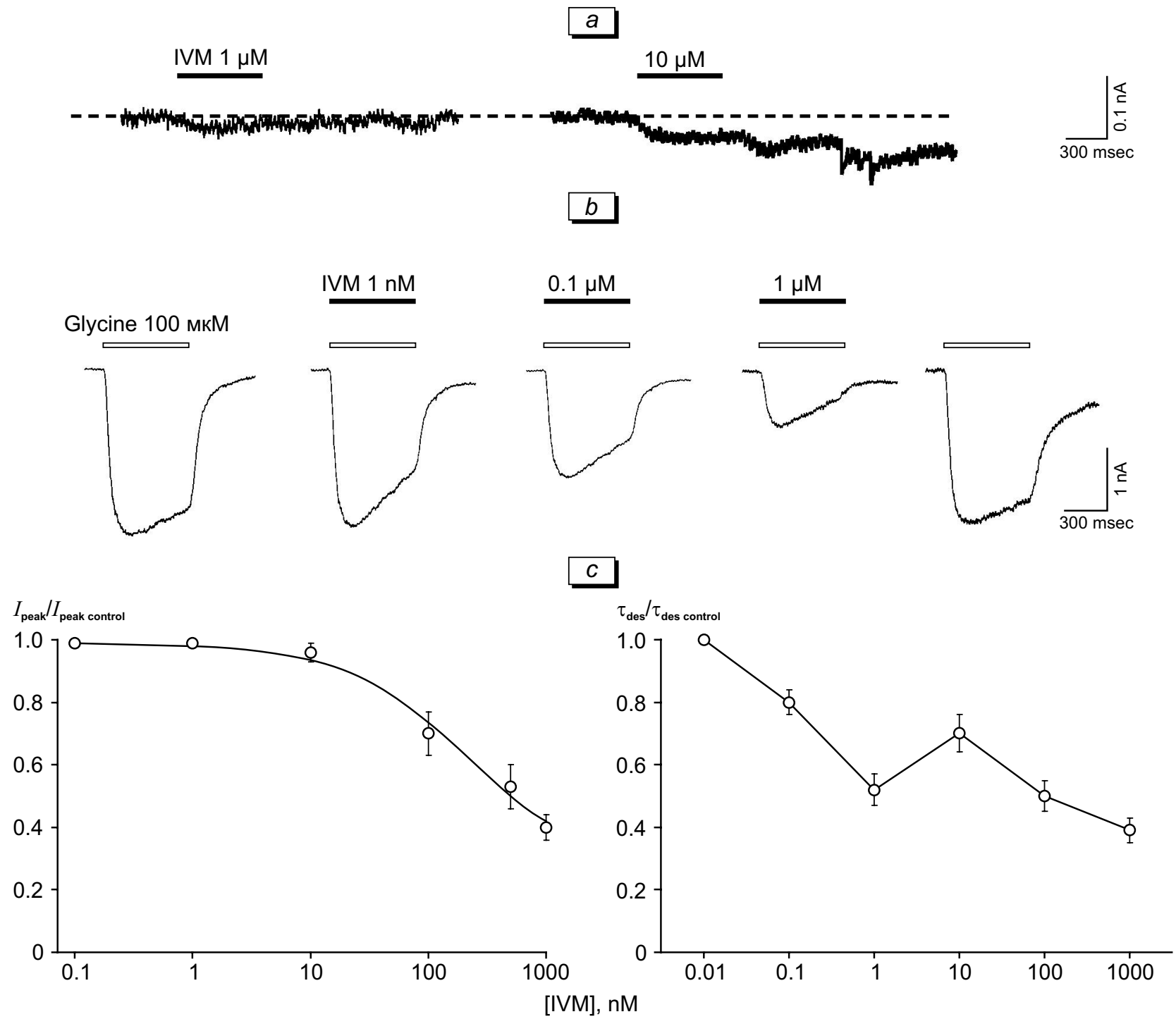

Fig. 1. Effect of IVM on holding current and $I_{\text {Gly }}$ induced by $100 \mu \mathrm{M}$ glycine. a) Effect of 1 and $10 \mu \mathrm{M}$ IVM on holding current at

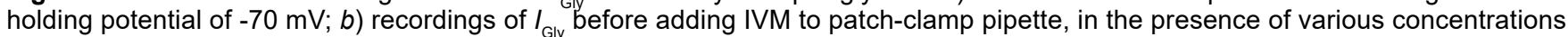
of IVM, and after removing IVM from the pipette; $c$ ) normalized plots of dose-dependent effect of IVM on peak amplitude $\left(I_{\text {peak }}\right)$ and desensitization time constant $\left(\mathrm{T}_{\mathrm{des}}\right)$ of $I_{\mathrm{Gly}}$. 
characterized with EC $50=90 \pm 7 \mu \mathrm{M}$. $I_{\mathrm{Gly}}$ was induced with glycine at concentrations of 100 or $500 \mu \mathrm{M}$, which were close to $\mathrm{EC}_{50}$ or to concentration evoking maximal $I_{\text {Gly }}$, respectively.

In preliminary experiments, the effect of IVM on holding current was examined. At low concentrations $(\leq 1 \mu \mathrm{M})$, a short-term $(600 \mathrm{msec})$ application of IVM produced no effect on this current (Fig. 1,a). Application of IVM in higher concentration $(10 \mu \mathrm{M})$ induced a slow inward current, that was did not return to initial level throughout the experiment (Fig. 1, a). According to [9], IVM-induced current results in accumulation of cytoplasmic chloride and shifts the chloride equilibrium potential. Evidently, it is problematic to examine $I_{\mathrm{Gly}}$, which is carried out by chloride ions. Logically, further experiments focusing on the effect of IVM on $I_{\text {Gly }}$ were carried out at low IVM concentrations (0.1$1000 \mathrm{nM}$ ), which did not evoke ionic current per se.

In further experiments, we studied the effect of IVM on $I_{\text {Gly }}$ caused by application of $100 \mu \mathrm{M}$ glycine. To this end, IVM was supplemented to glycinecontaining pipette and applied to neurons with gly- cine for 600 msec. In all examined neurons $(n=12)$, application of IVM resulted in rapid, reversible, and dose-dependent inhibition of $I_{\text {Gly }}$ (Fig. 1, b). IVM produced two effects manifested by a decrease in peak amplitude of $I_{\text {Gly }}$ and acceleration of its desensitization. The normalized dose-dependence plots for peak amplitude $\left(I_{\text {peak }}\right)$ and $\tau_{\text {des }}$ of $I_{\text {Gly }}$ show that the threshold concentrations of IVM affecting $\tau_{\text {des }}$ and $I_{\text {peak }}$ are 0.1 and $100 \mathrm{nM}$, respectively. The parameters of dosedependence plots for both IVM effects also differed (Fig. 1, c). For $I_{\text {peak }}$, this plot had the form of a smooth regression curve with maximum effect at $1000 \mathrm{nM}$ IVM, while the dose-dependence plot for $\tau_{\text {des }}$ was Nshaped with two maxima at 1 and $1000 \mathrm{nM}$ IVM. In relation to control levels, $I_{\text {peak }}$ at $1000 \mathrm{nM}$ IVM was $0.41 \pm 0.04(p<0.0001, n=8)$, while the values of $\tau_{\text {des }}$ at $1 \mathrm{nM}$ and $1000 \mathrm{nM}$ IVM were $0.52 \pm 0.05(p<0.0001)$ and $0.39 \pm 0.04(p<0.0001)$, respectively.

The next experiments were carried out with $I_{\mathrm{Gly}}$ induced by $500 \mu \mathrm{M}$ glycine (Fig. 2). They showed that elevation of glycine concentration weakened the effect of IVM on $I_{\text {peak }}$, but did not change the effect of

a
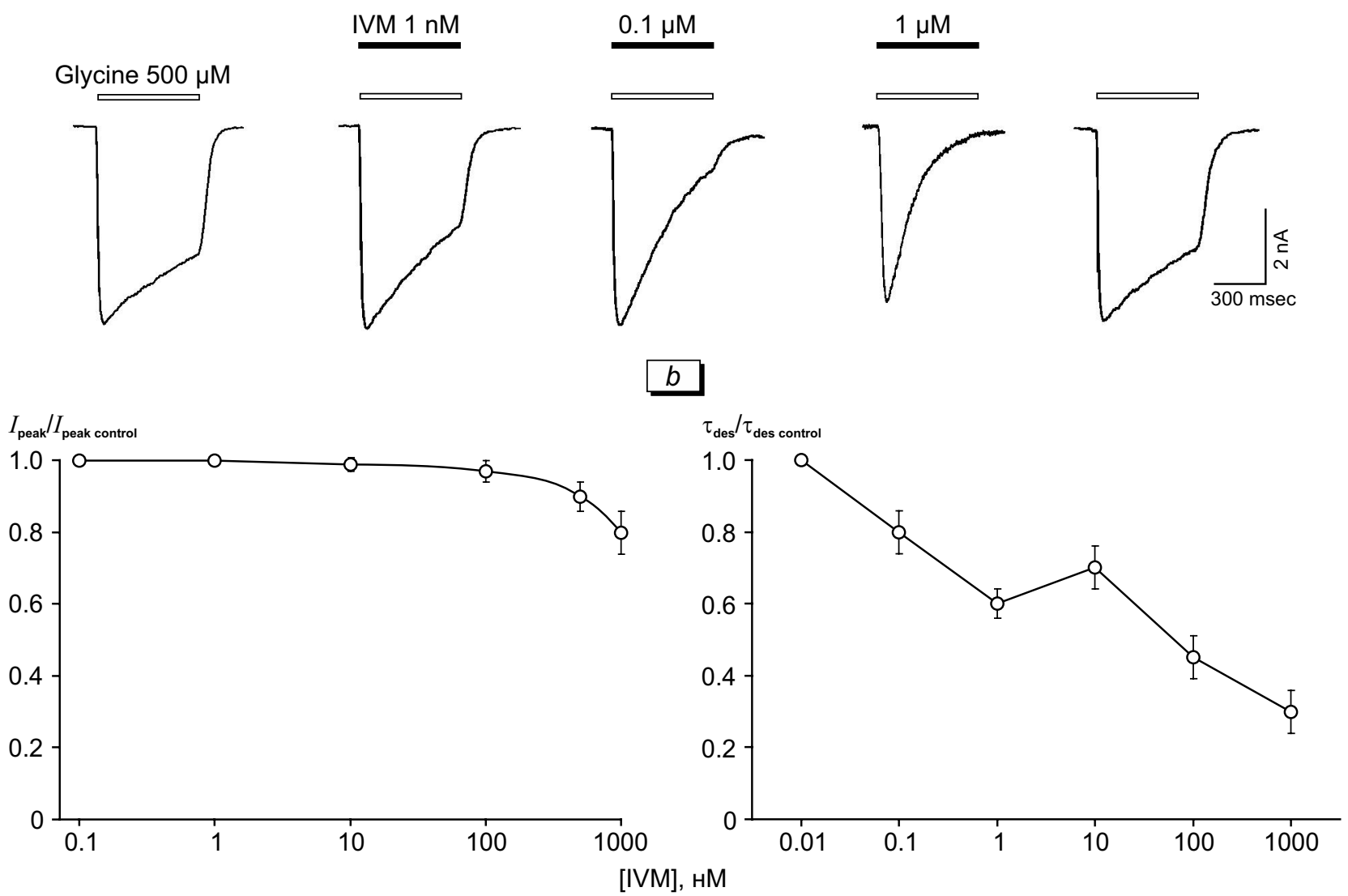

Fig. 2. Effect of IVM on $I_{\text {Gly }}$ induced by $500 \mu \mathrm{M}$ glycine. a) Recordings of $I_{\text {Gly }}$ before adding IVM to patch clamp pipette, in the presence of various concentrations of IVM, and after removing IVM from the pipette; $b$ ) normalized plots of dose-dependent effect of IVM on peak amplitude $\left(I_{\text {peak }}\right)$ and the time constant of desensitization ( $\tau$ des) of $I_{\text {Gly }}$ 
IVM on $\tau_{\text {des }}$. At a glycine concentration of $500 \mu \mathrm{M}$, the threshold IVM concentration affecting $I_{\text {peak }}$ was $500 \mathrm{nM}$, while $I_{\text {peak }}$ at $1000 \mathrm{nM}$ IVM was $0.81 \pm 0.06$ relatively to the control level $(p<0.05, n=7)$, which was significantly higher than the corresponding value obtained with $100 \mu \mathrm{M}$ glycine $(p<0.01, n=7)$. In this case, the values of $\tau_{\text {des }}$ at 1 and $1000 \mathrm{nM}$ IVM were $0.60 \pm 0.04(p<0.0001)$ and $0.29 \pm 0.06(p<0.0001)$, respectively, relatively to control value, and they did not significantly differ from the corresponding $\tau_{\text {des }}$ values obtained at $100 \mu \mathrm{M}$ glycine.

It was established that IVM activates chloride channels and elevates cytoplasmic chloride [9], and both effects are viewed as important mechanisms of physiological action of this drug. In neurons and muscle cells of invertebrates, IVM enhances the chloride current flowing through glutamate-activated chloride channels (GluClC) [14], which explains its antiparasitic effect. No GluClC were found on vertebrate animal cells although at least five other types of chloride channels were described that are regulated by various factors, including neurotransmitters (GABA, glycine), cAMP-dependent phosphorylation, membrane potential, $\mathrm{Ca}^{2+}$ ions, and intracellular turgor [12]. In various cells (frog oocytes, HEK293, rat cortical neurons, and fibroblasts) IVM at high concentrations induces a slow and irreversible chloride current, which cannot be blocked by picrotoxin and, therefore, cannot be explained by potentiation of GABA- or glycine-activated receptors [8]. Here, IVM $(10 \mu \mathrm{M})$ induced a slow and irreversible current in native neurons, which cannot be eliminated by washing. However, the type of chloride channels or pores responsible for this current is presently unclear.

The effect of IVM on GABA- and glycine-activated chloride current $\left(I_{\mathrm{GABA}}\right.$ and $\left.I_{\mathrm{Gly}}\right)$ was studied in electrophysiological experiments both on recombinant receptors expressed in oocytes or HEK293 cells, and on native neurons and fibroblasts $[4,8]$. It was found that the effects of IVM on $I_{\mathrm{GABA}}$ and $I_{\mathrm{Gly}}$ in recombinant receptors and native cells were different. IVM augmented IGABA, recorded in recombinant receptors and native neurons of rat cortex, but diminished this current in fibroblasts [4]. In recombinant GlyRs, IVM exerted the stimulating effect on $I_{\text {Gly }}[8]$, whereas it inhibited this current in rat cortical neurons [4]. Therefore, the recombinant receptors in oocytes or kidney cells (HEK293) have different pharmacological properties in comparison with those of native neurons. Evidently, further studies of IVM effects exerted on ligand-operated chloride channels should be carried out on native neurons.

In pyramidal neurons of rat hippocampus, IVM at low concentration did not induce its own chloride current but decreased $I_{\mathrm{Gly}}$. IVM exerted dual effect on $I_{\mathrm{Gly}}$ : it decreased the peak amplitude of $I_{\mathrm{Gly}}$ and $\tau_{\mathrm{des}}$. The threshold concentration of IVM for affecting $\tau_{\text {des }}$ was smaller by 3 orders of magnitude than that for acting on the peak amplitude of $I_{\mathrm{Gly}}$. The dose-dependence plot for the effect of IVM on $\tau_{\text {des }}$ was $\mathrm{N}$-shaped. The effect of IVM on peak amplitude of $I_{\text {Gly }}$ decreased when concentration of glycine increased, while its effect on $\tau_{\text {des }}$ did not change, which attests to independent nature of both effects. Probably, attenuation of $I_{\text {Gly }}$ peak amplitude is underlain by a competitive mechanism, in contrast to IVM effect on desensitization of $I_{\text {Gly }}$

Enhanced sensitivity of $\tau_{\text {des }}$ to IVM, N-shape of its dose-dependence plot, and stability of this effect despite increasing glycine concentration are similar to the effects of other drugs (cyclic nucleotides, beta-amyloid peptide, and lithium ions) exerted on $I_{\mathrm{Gly}}$, which we described previously in isolated pyramidal neurons of rat hippocampus $[2,10,11]$. Overall, these results suggest that GlyR in these neurons has a nonspecific site located near the desensitization gate of chloride channel, which is able to bind various drugs with different affinities.

Our study showed that antiviral drug IVM is an effective antagonist of neuronal GlyR. The present data not only widen our views on pharmacological properties of GlyR, but they can also be useful in analyzing the mechanisms of side effects, which can emerge when using IVM as antiparasitic, antiviral, or anticancer agent.

This work was supported by the Russian Foundation for Basic Research (grant No. 20-015-00215).

\section{REFERENCES}

1. Shuvaev AN, Salmin VV, Kuvacheva NV, Pozhilenkova EA, Salmina AB. Modern tendencies in the development of the patchclamp technique: new opportunities for neuropharmacology and neurobiology. Annaly Klin. Eksp. Nevrol. 2015;9(4):54-58. Russian.

2. Bukanova JV, Solntseva EI, Kondratenko RV, Skrebitsky VG. Glycine receptor in hippocampal neurons as a target for action of extracellular cyclic nucleotides. Neurosci. Lett. 2014;561:58-63.

3. Chaccour C, Hammann F, Ramón-García S, Rabinovich NR. Ivermectin and COVID-19: keeping rigor in times of urgency. Am. J. Trop. Med. Hyg. 2020;102(6):1156-1157.

4. Dawson GR, Wafford KA, Smith A, Marshall GR, Bayley PJ, Schaeffer JM, Meinke PT, McKernan RM. Anticonvulsant and adverse effects of avermectin analogs in mice are mediated through the gamma-aminobutyric acid(A) receptor. J. Pharmacol. Exp. Ther. 2000;295(3):1051-1060.

5. Juarez M, Schcolnik-Cabrera A, Dueñas-Gonzalez A. The multitargeted drug ivermectin: from an antiparasitic agent to a repositioned cancer drug. Am. J. Cancer Res. 2018;8(2):317-331.

6. Laing R, Gillan V, Devaney E. Ivermectin - old drug, new tricks? Trends Parasitol. 2017;33(6):463-472. 
7. Liu J, Zhang K, Cheng L, Zhu H, Xu T. Progress in understanding the molecular mechanisms underlying the antitumour effects of ivermectin. Drug Des. Devel. Ther. 2020;14:285296.

8. Shan Q, Haddrill JL, Lynch JW. Ivermectin, an unconventional agonist of the glycine receptor chloride channel. J. Biol. Chem. 2001;276(16):12556-12564.

9. Sharmeen S, Skrtic M, Sukhai MA, Hurren R, Gronda M, Wang X, Fonseca SB, Sun H, Wood TE, Ward R, Minden MD, Batey RA, Datti A, Wrana J, Kelley SO, Schimmer AD. The antiparasitic agent ivermectin induces chloride-dependent membrane hyperpolarization and cell death in leukemia cells. Blood. 2010;116(18):3593-3603.

10. Solntseva EI, Bukanova JV, Kondratenko RV, Skrebitsky VG. Lithium ions in nanomolar concentration modulate glycine- activated chloride current in rat hippocampal neurons. Neurochem. Int. 2016;94:67-73.

11. Solntseva EI, Bukanova JV. Use-dependent inhibition of glycine-activated chloride current in rat neurons by $\beta$-amyloid peptide pretreated with hexafluoroisopropanol. Neuroreport. 2017;28(10):579-583.

12. Verkman AS, Galietta LJ. Chloride channels as drug targets. Nat. Rev. Drug Discov. 2009;8(2):153-171.

13. Weir GA, Middleton SJ, Clark AJ, Daniel T, Khovanov N, McMahon SB, Bennett DL. Using an engineered glutamate-gated chloride channel to silence sensory neurons and treat neuropathic pain at the source. Brain. 2017;140(10):2570-2585.

14. Wolstenholme AJ, Rogers AT. Glutamate-gated chloride channels and the mode of action of the avermectin/milbemycin anthelmintics. Parasitology. 2005;131(Suppl):S85-S95. 